Pacific Journal of Mathematic

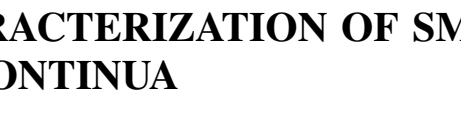




\title{
A QUASI ORDER CHARACTERIZATION OF SMOOTH CONTINUA
}

\author{
LEWIS LUM
}

\begin{abstract}
L. E. Ward, Jr. characterized a generalized tree as a compact Hausdorff space which admits a partial order satisfying certain conditions. An analogous characterization of smooth continua, in terms of quasi ordered topological spaces, is obtained.
\end{abstract}

A quasi order on a topological space $X$ is a reflexive and transitive binary relation $\leqq$. If this relation is also antisymmetric it is called a partial order. The quasi order $\leqq$ is closed if $\{(x, y) \in X \times$ $X \mid x \leqq y\}$ is a closed subset of the product space $X \times X$.

For each $x \in X$, the set $L(x)=\{y \in X \mid y \leqq x\}$ (respectively, $M(x)=\{y \in X \mid x \leqq y\}$ ) is called the set of predecessors (respectively, successors) of $x$. Let $E(x)=L(x) \cap M(x)$ and note that $\leqq$ is a partial order if and only if each $E(x)$ is a singleton. In case $\leqq$ is closed, the sets $L(x), M(x)$, and $E(x)$ are closed subsets of $X$.

If $x \leqq y$ and $x \notin E(y)$ we write $x<y$. The quasi order $\leqq$ is order dense if whenever $x<y$, there exists $z \in X$ such that $x<z<y$.

Let $S$ be a subset of $X$. An element $z \in S$ is a zero of $S$ if $z \leqq x$ for each $x \in S$. If $x \leqq y$ or $y \leqq x$ for all $x, y \in S$, then $S$ is called a chain.

We define the equivalence relation $\rho$ on $X$ by

$$
(x, y) \in \rho \text { if and only if } E(x)=E(y) .
$$

Let $\phi: X \rightarrow X / \rho$ denote the natural quotient map.

A continuum (= compact connected Hausdorff space) $X$ is hereditarily unicoherent at the point $p$ [2] if for each $x \in X$, there exists a unique subcontinuum of $X$, denoted $[p, x]$, irreducible between $p$ and $x$. We say $X$ is hereditarily unicoherent if it is hereditarily unicoherent at each of its points.

If the continuum $X$ is hereditarily unicoherent at $p$ then $X$ admits a very natural quasi order $\leqq_{p}$, called the weak cut point order with respect to $p$ :

$$
x \leqq_{p} y \text { if and only if } x \in[p, y] .
$$

Note that for each $x \in X, L(x)=[p, x]$.

The continuum $X$ is smooth if there exists a point $p \in X$ such that $X$ is hereditarily unicoherent at $p$ and the quasi order $\leqq_{p}$ is closed. By [1], Theorem 3.1, p. 65, this definition is equivalent to 
Gordh's original definition [2]. To emphasize the point $p$ we will of ten write " $X$ is smooth at $p$ ". A generalized tree is a hereditarily unicoherent, arcwise connected ${ }^{1}$ smooth continuum. Ward's original definition [6] is stated here as Theorem 1. According to [4] the definitions are equivalent.

THEOREM 1. The compact Hausdorff space $X$ is a generalized tree if and only if $X$ admits a partial order $\leqq$ such that

(1) $\leqq$ is closed;

(2) $\leqq$ is order dense;

(3) if $x, y \in X$, then $L(x) \cap L(y)$ is a nonempty chain;

(4) if $Y$ is a closed and connected subset of $X$, then $Y$ contains a zero.

It follows that $\leqq$ is the weak cut point order with respect to $p$ where $\{p\}=\bigcap\{L(x) \mid x \in X\}$ and $L(x)=[p, x]$.

It is the purpose of this paper to establish an analogous characterization for smooth continua.

Consider the following properties that a quasi order $\leqq$ on a space $X$ may possess:

(i) $\leqq$ is closed;

(ii) $\leqq$ is order dense;

(iii) there exists $p \in \bigcap\{L(x) \mid x \in X\}$ and each $L(x)$ is a chain;

(iv) if $Y$ is a closed connected subset of $X$, then $Y$ contains a zero;

(v) $E(x)$ is connected for each $x \in X$;

(vi) if $Y$ is a closed connected subset of $X$ and $p \in Y$, then $E(y) \subseteq Y$ for each $y \in Y$.

THEOREM 2. Let $X$ be a compact Hausdorff space which admits a quasi order $\leqq$ satisfying (i)-(vi). Then $X$ is a continuum which is smooth at $p$.

The theorem will be proved via a series of lemmas. Unless otherwise stated assume $X$, $\leqq$, and $p$ are as above. Observe that (vi) implies $p$ is the unique zero of $X$.

LEMMA 1. The space $X / \rho$ is compact Hausdorff and the map $\phi: X \rightarrow X / \rho$ is monotone.

Proof. First note that $\{E(x) \mid x \in X\}$ is a pairwise disjoint closed covering of $X$. From Theorem 2, [7], p. 147, and [3], p. 132, we infer $\{E(x) \mid x \in X\}$ is an upper semicontinuous decomposition of $X$.

\footnotetext{
${ }^{1}$ An arc is a continuum (not necessarily metrizable) with exactly two noncut points.
} 
By Theorem 3-33, [3], p. 133, $X / \rho$ is compact Hausdorff. Finally, it follows from (i) and (v) that $\phi^{-1}(\phi(x))=E(x)$ is closed and connected; hence $\phi: X \rightarrow X / \rho$ is monotone.

The quasi order $\leqq$ on $X$ induces a relation $\leqq^{\prime}$ on $X / \rho$ defined by

$$
\phi(x) \leqq{ }^{\prime} \phi(y) \text { if and only if } x \leqq y .
$$

For the sake of clarity let $L^{\prime}(\phi(x))$ denote the set of predecessors of $\phi(x)$ in $X / \rho$.

LEMmA 2. The space $X / \rho$ is a generalized tree which is smooth at $\phi(p)$. Moreover, $\leqq$ is the weak cut point order with respect to $\phi(p)$ and $L^{\prime}(\phi(x))$ is the unique subcontinuum of $X / \rho$ irreducible between $\phi(p)$ and $\phi(x)$.

Proof. It is straightforward to verify that $\leqq^{\prime}$ is a partial order satisfying the hypotheses of Theorem 1.

Lemma 3. The space $X$ is a continuum. In particular, $L(x)$ is closed and connected for each $x \in X$.

Proof. Since $L(x)$ is the inverse image of $L^{\prime}(\phi(x)) \cong X / \rho$ under the monotone map $\phi: X \rightarrow X / \rho$ it follows from Theorem 9, [5], p. 131, that $L(x)$ is closed and connected. Since $p \in \bigcap\{L(x) \mid x \in X\}$ and $X=\bigcup\{L(x) \mid x \in X\}$, the lemma is proved.

Lemma 4. If $Y$ is a subcontinuum of $X$ and $p \in Y$, then $\phi^{-1}(\phi(Y))=Y$.

Proof. We show only $\phi^{-1}(\phi(Y)) \subseteq Y$. If $z \in \phi^{-1}(\phi(Y))$ there exists $y \in Y$ such that $\phi(y)=\phi(z)$. By (vi)

$$
z \in E(z)=E(y) \subseteq Y \text {. }
$$

Lemma 5. The continuum $X$ is hereditarily unicoherent at $p$.

Proof. Let $x$ be a fixed, but arbitrary, point in $X$ and let $Y \cong X$ be a subcontinuum irreducible between $p$ and $x$. Then $\phi(Y) \cong X / \rho$ is a subcontinuum containing $\phi(p)$ and $\phi(x)$. Since $X / \rho$ is a generalized tree, $L^{\prime}(\phi(x)) \leqq \phi(Y)$. It follows from

$$
L(x)=\phi^{-1}\left(L^{\prime}(\phi(x)) \leqq \phi^{-1}(\phi(Y))=Y\right.
$$

and Lemma 3 that $L(x)=Y$. That is, $L(x)$ is the unique subcontinuum of $X$ irreducible between $p$ and $x$.

We have shown that the space $X$ is a continuum which is here- 
ditarily unicoherent at $p$. Moreover, $[p, x]=L(x)$ for each $x \in X$. It follows immediately that $\leqq$ is the weak cut point order with respect to $p$. Since $\leqq$ is closed by hypothesis, the proof of Theorem 2 is complete.

The converse of Theorem 2 is also true. Before proceeding, however, we need a few results about smooth continua. The reader is referred to [2] for the details.

THeOREM 3. If the continuum $X$ is smooth at $p$ then $X / \rho$ is a generalized tree which is smooth at $\phi(p)$, the map $\phi: X \rightarrow X / \rho$ is monotone, and $\operatorname{int}_{X} E(x)=\square \cdot{ }^{2}$

LemMa 6. If the continuum $X$ is smooth at $p$ then $x \leqq{ }_{p} y$ (respectively, $\left.x<_{p} y\right)$ if and only if $\phi(x) \leqq_{\phi(p)} \phi(y)$ (respectively, $\phi(x)<_{\phi(p)}$ $\phi(y))$. Moreover, if $Y$ is a subcontinuum of $X$ and $p \in Y$, then $\phi^{-1}(\phi(Y))=Y$.

THEOREM 4. If the continuum $X$ is smooth at $p$ then $\leqq_{p}$ satisfies (i)-(vi).

Proof. It is immediate that (i) and (vi) hold. Since $E(x)$ is the inverse image of the point $\phi(x)$ under the monotone map $\phi: X \rightarrow X / \rho$, (v) holds. Conditions (ii) and (iii) follow from Lemma 6 and the fact that $L(x)=\phi^{-1}\left(L^{\prime}(\phi(x))\right.$. Finally to show (iv) holds, let $Y$ be a subcontinuum of $X$. Then $\phi(Y)$ is a subcontinuum of the generalized tree $X / \rho$. Let $z \in X$ be such that $\phi(z)$ is a zero of $\phi(Y)$. Choose any

$$
y \in \phi^{-1}(\phi(z)) \cap Y=E(z) \cap Y .
$$

It follows from Lemma 6 that $y$ is a zero of $Y$.

Observe that condition (iii) is equivalent to condition (3) of Ward's theorem. The paraphrase was inserted as a matter of convenience, since the point $p$ appears in condition (vi).

We remark that each of conditions (i)-(vi) is independent of the remaining five. We include here examples to clarify the necessity of the last two conditions. The omitted details are left to the reader. Let $\leqq$ denote the natural partial order on the real numbers.

Example 1. (Due to J. Ladwig.) Let $X$ denote the Cantor Set and let $\left\{\left(a_{n}, b_{n}\right) \mid n=1,2, \cdots\right\}$ be the collection of "deleted intervals"; i.e.,

$$
X=[0,1]-\bigcup_{n=1}^{\infty}\left(a_{n}, b_{n}\right)
$$

${ }^{2}$ "int ${ }_{X}$ " denotes interior in the space $X$ and " $\square$ " denotes the empty set. 
and for $n=1,2, \cdots$

$$
\left[a_{n}, b_{n}\right] \cap X=\left\{a_{n}, b_{n}\right\} \text {. }
$$

Define $x \leqq y$ if and only if $x \leqq \leqq_{0} y$ or $x$ and $y$ are endpoints of a common deleted interval. The quasi order $\leqq$ on $X$ satisfies (i)-(iv) and (vi) but not (v).

EXAMPLE 2. In the plane let $X$ be the triangle with vertices $p=(0,0),(1,0)$, and $(1,1)$. Define $(x, y) \leqq(u, v)$ if and only if $x \leqq_{0} u$. Then $\leqq$ on $X$ satisfies (i)-(v) but not (vi); e.g., take $Y=[0,1] \times\{0\}$.

COROLLARY 1. Let $X$ be a continuum which is smooth at $p$. Then $\leqq_{p}$ is a partial order if and only if $X$ is a generalized tree which is smooth at $p$.

Proof. If $\leqq_{p}$ is a partial order then each $E(x)$ is degenerate and conditions (i)-(vi) reduce to (1)-(4) of Theorem 1 . The converse is trivial since each $L(x)$ is an arc for each $x \in X$.

It is necessary that the continuum $X$ in Corollary 1 be smooth at $p$ as the example below shows.

EXAMPLE 3 . In the plane let

$$
\begin{aligned}
& A=\left\{\left(x, \sin \frac{1}{x}\right) \mid 0<x \leqq 1\right\}, \\
& B=\{0\} \times[-1,1], \\
& C=[-1,0] \times\{-1\} .
\end{aligned}
$$

The continuum $X=A \cup B \cup C$ is clearly not a generalized tree. However, $X$ is hereditarily unicoherent and $\leqq_{p}$ is a partial order for $p=(-1,1)$.

Finally observe that in the presence of conditions (i) and (iii)-(vi), condition (ii) is equivalent to

$$
\text { (ii') } \operatorname{int}_{L(x)} E(x)=\square \text { for each } x \in X-\{p\} \text {. }
$$

For if $X$ is smooth at $p$ then so is $L(x)$; thus (ii') is a consequence of Theorem 3. Conversely, we show (i), (ii'), and (iii) imply (ii). Suppose $x, y \in X$ are such that $x<y$ and $x<z<y$ for no $z \in X$. Then $L(y)-L(x)$ is a nonempty open (in $L(y)$ ) subset of $E(y)$, contradicting $\left(\mathrm{ii}^{\prime}\right)$.

\section{REFERENCES}

1. G. R. Gordh, Jr., Concerning closed quasi-orders on hereditarily unicoherent continua, Fund. Math., 78 (1973), 61-73. 
2. G. R. Gordh, Jr., On decompositions of smooth continua, Fund. Math., 75 (1972), 51-60.

3. J. G. Hocking and G. S. Young, Topology, Addison-Wesley, Reading, Mass., 1961.

4. R. J. Koch and I. S. Krule, Weak cut-point ordering on hereditarily unicoherent continua, Proc. Amer. Math. Soc., 11 (1960), 679-681.

5. K. Kurtowski, Topology II, PWN-Academic Press, Warsaw-New York, 1968.

6. L. E. Ward, Jr., Mobs, trees, and fixed points, Proc. Amer. Math. Soc., 8 (1957), 798-804.

7. — Partially ordered topological spaces, Proc. Amer. Math. Soc., 5 (1954), 144-161.

Received June 29, 1973 and in revised form October 19, 1973. This research constitutes a part of the author's dectoral dissertation written under L. E. Ward, Jr., at the University of Oregon.

UNIVERSITY OF OREGON

AND

University of Tennessee

Present address: Salem College

Winston-Salem, N.C. 


\section{PACIFIC JOURNAL OF MATHEMATICS}

\section{EDITORS}

RICHARD ARENS (Managing Editor)

University of California

Los Angeles, California 90024

\section{J. DUGUNDJI}

Department of Mathematics University of Southern California Los Angeles, California 90007

D. Gilbarg and J. Milgram

Stanford University

Stanford, California 94305

University of Washington
Seattle, Washington 98105

ASSOCIATE EDITORS
E. F, BECKENBACH
B. H. NEUMANN
F. WOLF
K. Yoshida

\section{SUPPORTING INSTITUTIONS}

\author{
UNIVERSITY OF BRITISH COLUMBIA \\ CALIFORNIA INSTITUTE OF TECHNOLOGY \\ UNIVERSITY OF CALIFORNIA \\ MONTANA STATE UNIVERSITY \\ UNIVERSITY OF NEVADA \\ NEW MEXICO STATE UNIVERSITY \\ OREGON STATE UNIVERSITY \\ UNIVERSITY OF OREGON \\ OSAKA UNIVERSITY
}

\author{
UNIVERSITY OF SOUTHERN CALIFORNIA \\ STANFORD UNIVERSITY \\ UNIVERSITY OF TOKYO \\ UNIVERSITY OF UTAH \\ WASHINGTON STATE UNIVERSITY \\ UNIVERSITY OF WASHINGTON \\ * * * * \\ AMERICAN MATHEMATICAL SOCIETY \\ NAVAL WEAPONS CENTER
}

The Supporting Institutions listed above contribute to the cost of publication of this Journal, but they are not owners or publishers and have no responsibility for its content or policies.

Mathematical papers intended for publication in the Pacific Journal of Mathematics should be in typed form or offset-reproduced, (not dittoed), double spaced with large margins. Underline Greek letters in red, German in green, and script in blue. The first paragraph or two must be capable of being used separately as a synopsis of the entire paper. Items of the bibliography should not be cited there unless absolutely necessary, in which case they must be identified by author and Journal, rather than by item number. Manuscripts, in duplicate if possible, may be sent to any one of the four editors. Please classify according to the scheme of Math. Rev. Index to Vol. 39. All other communications to the editors should be addressed to the managing editor, or Elaine Barth, University of California, Los Angeles, California, 90024.

100 reprints are provided free for each article, only if page charges have been substantially paid. Additional copies may be obtained at cost in multiples of 50 .

The Pacific of Journal Mathematics is issued monthly as of January 1966. Regular subscription rate: $\$ 72.00$ a year (6 Vols., 12 issues). Special rate: $\$ 36.00$ a year to individual members of supporting institutions.

Subscriptions, orders for back numbers, and changes of address should be sent to Pacific Journal of Mathematics, 103 Highland Boulevard, Berkeley, California, 94708.

PUBLISHED BY PACIFIC JOURNAL OF MATHEMATICS, A NON-PROFIT CORPORATION

Printed at Kokusai Bunken Insatsusha (International Academic Printing Co., Ltd.), 270, 3-chome Totsuka-cho, Shinjuku-ku, Tokyo 160, Japan.

Copyright (C) 1973 by Pacific Journal of Mathematics Manufactured and first issued in Japan 


\section{Pacific Journal of Mathematics}

\section{Vol. 53, No. $2 \quad$ April, 1974}

Kenneth Abernethy, On characterizing certain classses of first countable spaces by

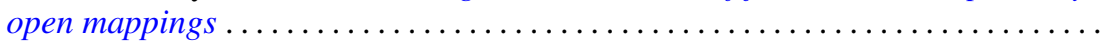

Ross A. Beaumont and Donald Lawver, Strongly semisimple abelian groups .......

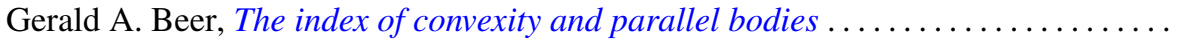

Victor P. Camillo and Kent Ralph Fuller, On Loewy length of rings ..............

Stephen LaVern Campbell, Linear operators for which $T^{*} T$ and $T T^{*}$ commute.

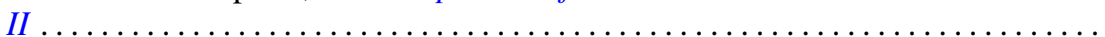

Charles Kam-Tai Chui and Philip Wesley Smith, Characterization of a function by

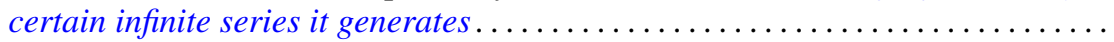

Allan L. Edelson, Conjugations on stably almost complex manifolds . ...........

Patrick John Fleury, Hollow modules and local endomorphism rings . . ..........

Jack Tilden Goodykoontz, Jr., Connectedness im kleinen and local connectedness in

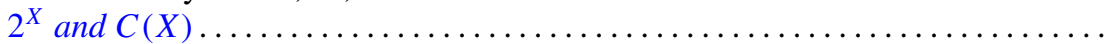

Robert Edward Jamison, II, Functional representation of algebraic intervals .......

Athanassios G. Kartsatos, Nonzero solutions to boundary value problems for

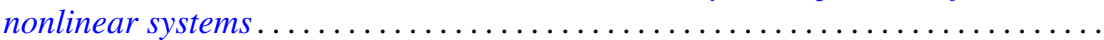

Soon-Kyu Kim, Dennis McGavran and Jingyal Pak, Torus group actions on simply

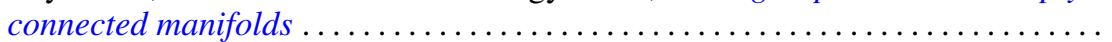

David Anthony Klarner and R. Rado, Arithmetic properties of certain recursively

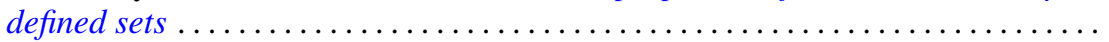

Ray Alden Kunze, On the Frobenius reciprocity theorem for square-integrable

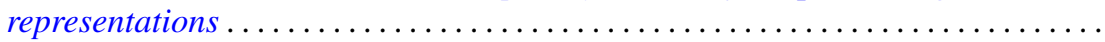

John Lagnese, Existence, uniqueness and limiting behavior of solutions of a class of differential equations in Banach space...

Teck Cheong Lim, A fixed point theorem for families on nonexpansive mappings Lewis Lum, A quasi order characterization of smooth continua

Andy R. Magid, Principal homogeneous spaces and Galois extensions . .

Charles Alan McCarthy, The norm of a certain derivation ..... . .

Louise Elizabeth Moser, On the impossibility of obtaining $S^{2} \times S^{1}$ by elementary surgery along a knot. .

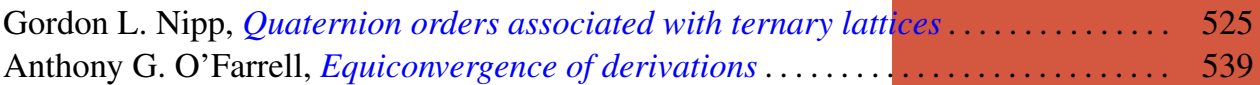

Dorte Olesen, Derivations of $A W^{*}$-algebras are inner . . . . . . . . . . . . . . . 555

Dorte Olesen and Gert Kjærgaard Pedersen, Derivations of $C^{*}$-algebras have

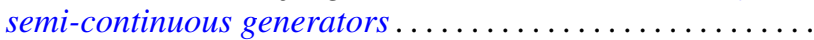

Duane O’Neill, On conjugation cobordism.

Chull Park and S. R. Paranjape, Probabilities of Wiener paths crossing differentiable

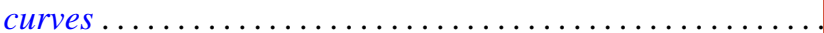

Edward Ralph Rozema, Almost Chebyshev subspaces of $L^{1}(\mu$;

Lesley Millman Sibner and Robert Jules Sibner, A note on the Atiyah-Bott fixed

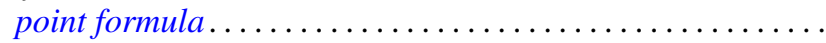

Betty Salzberg Stark, Irreducible subgroups of orthogonal groups generated by

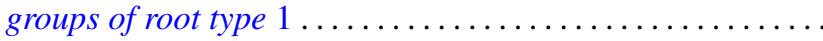

N. Stavrakas, A note on starshaped sets, $(k)$-extreme points and the half ray

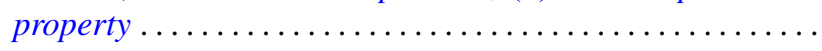

Carl E. Swenson, Direct sum subset decompositions of $Z \ldots \ldots$ 